УДК 159.9

\title{
НАРУШЕНИЕ ПИЩЕВОГО ПОВЕДЕНИЯ СУБЪЕКТОВ В ДОКЛИНИЧЕСКИЙ И КЛИНИЧЕСКИЙ ПЕРИОДЫ
}

\author{
Хох Ирина Рудольфовна \\ к.пс.н., доцент \\ Федорова Светлана Сергеевна
}

ФГБОУ ВО «Башкирский государственный университет»

\begin{abstract}
Аннотация: В статье представлен сравнительный анализ исследования женщин, находящихся в доклиническом и клиническом периодах развития расстройства пищевого поведения по типу анорексии и булимии и имеющих различия в поведенческих симптомах, в особенностях пищевого поведения.
\end{abstract}

Ключевые слова: Расстройство пищевого поведения, анорексия, булимия, алекситимия, перфекционизм.

\section{EATING BEHAVIOR DISORDERS OF SUBJECTS IN THE PRE-CLINICAL AND CLINICAL PERIODS}

\section{Khohk Irina Rudolfovna Fedorova Svetlana Sergeevna}

\begin{abstract}
The article presents a comparative analysis of the study of women who are in the preclinical and clinical periods of the development of anorexia and bulimia-type eating disorder and who have differences in behavioral symptoms, in the characteristics of eating behavior.
\end{abstract}

Key words: Eating disorder, anorexia, bulimia, alexithymia, perfectionism.

Под нарушениями пищевого поведения понимается класс психогенно обусловленных поведенческих синдромов, которые связаны с нарушениями в приеме пищи. Основные признаки расстройств приема пищи: чрезмерные опасения увеличения веса; значительные усилия по контролю за весом (строгая диета, вызывание рвоты, прием слабительных, избыточные физические упражнения); отрицание субъективной значимости проблемы веса и приема пищи [1, с. 41]. Однако пищевая потребность, будучи чисто биологической по 
своей природе у животных, у человека предстает в более сложном виде, являясь средством удовлетворения не только физиологических, но и различных социально-психологических потребностей. Так, прием пищи может быть средством разрядки психоэмоционального напряжения, компенсации неудовлетворенных потребностей, чувственного наслаждения, самоутверждения, общения, поддержания определенных ритуалов и т.д. [2, с. 45].

Таким образом, пищевое поведение человека находится в рамках континуума, включающего нормальные пищевые паттерны, эпизодические пищевые расстройства и, наконец, патологическое пищевое поведение. Среди патологических форм выделяют экстернальный, эмоциогенный, ограничительный типы пищевого поведения, а также наиболее тяжелые их проявления, такие как нервная анорексия и нервная булимия. Экстернальный тип пищевого поведения связан с повышенной чувствительностью к внешним стимулам потребления пищи. Человек с таким поведением ест в ответ не на внутренние стимулы, такие как пустой желудок, уровень глюкозы и свободных жирных кислот в крови и т. д., а на внешние - витрина продуктового магазина, хорошо накрытый стол, вид едящего человека, реклама пищевых продуктов и т. д. При эмоциогенном типе пищевого поведения стимулом к приему пищи также является не голод, а эмоциональный дискомфорт, который человек пытается облегчить с помощью высококалорийной еды, в которой преобладают продукты, богатые углеводами и жирами. В настоящее время в литературе даже появился такой термин, как «углеводная жажда», для удовлетворения которой человеку срочно необходима сладкая и жирная пища. При этом она подобна наркотику, и при ее отсутствии у человека развивается тягостное депрессивное состояние, чем-то напоминающее абстиненцию. Ограничительный тип поведения наблюдается при соблюдении чрезмерно строгой диеты, чередующейся с периодами компульсивного переедания на фоне развития так называемой «диетической депрессии». Наиболее тяжелыми формами нарушениями пищевого поведения считаются нервная анорексия и нервная булимия, которые относятся к очень серьезным нервно психическим расстройствам и лечатся уже с обязательным участием врачей-психиатров [3, с. 176].

Целью нашего исследования является изучение особенностей нарушения пищевого поведения субъектов в доклинический и клинический периоды.

Гипотезой исследования послужило предположение о том, что субъекты в доклинический и клинический периоды имеют различия: в поведенческих симптомах, в причинах нарушения пищевого поведения, в особенностях 
пищевого поведения, в способности вербализовывать эмоциональные состояния.

Выборку составили 90 женщин, в возрасте 29-38 лет, 45 человек было продиагностировано в доклинический период и 45 человек в клинический период при постановке соответствующего диагноза.

В клинической группе испытуемым были поставлены медицинские диагнозы, входящие в группу нозологий «Расстройства приема пищи (F50)» по МКБ -10 .

Для проверки гипотезы исследования в работе использованы следующие психодиагностические методики:

1. Скрининг-тест нарушений пищевого поведения: тест на анорексию и булимию - ЕАТ-26.

2. Голландский опросник пищевого поведения DEBQ.

3. Шкала оценки пищевого поведения.

4. Торонтская шкала алекситимии (TAS).

Математическая обработка результатов исследования производилась с помощью U-критерия Манна-Уитни и критерия ранговой корреляции Спирмена (расчеты проводились в Statistika, 6).

C помощью скрининг-теста нарушений пищевого поведения - EAT-26 мы выявили определённые поведенческие симптомы и внутренние установки, характерные для анорексии, булимии и других расстройств пищевого поведения. Результаты представлены на рис. 1. 


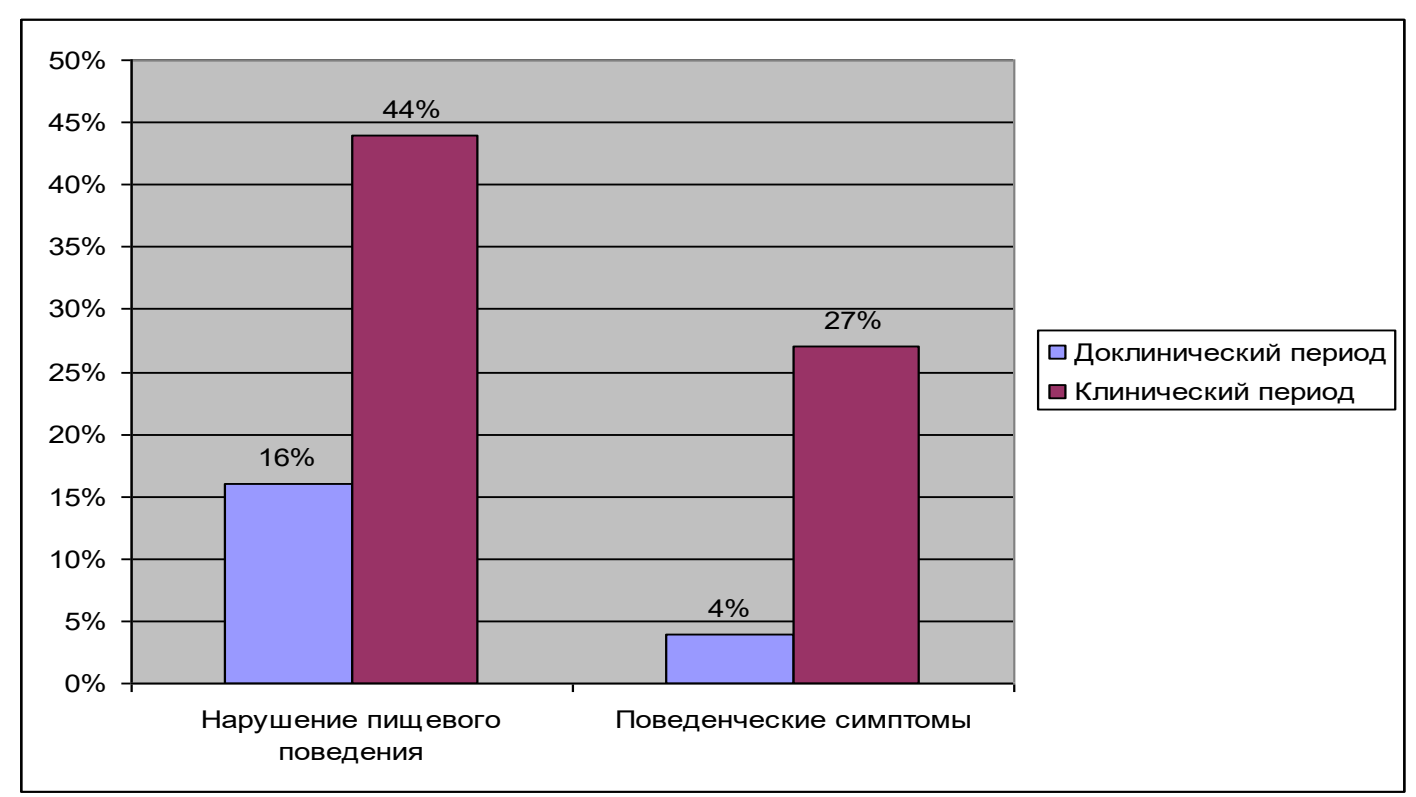

Рис. 1. Результаты диагностики нарушений пищевого поведения: на анорексию и булимию

По результатам тестирования мы выявили нарушение пищевого поведения у $44 \%$ испытуемых в клинический период и у $16 \%$ в доклинический период, что определяет высокую вероятность формирования расстройств пищевого поведения в дальнейшем. То есть можно говорить, что у них уже имеются какие-либо нарушения пищевого поведения, предположительно, симптомы анорексии или булимии. Также у $27 \%$ нашей выборки в клинический период и у 4\% в доклинический период были отмечены за последние 6 месяцев поведенческие симптомы, свойственные пищевым расстройствам. Среди поведенческих симптомов чаще всего были отмечены неконтролируемое объедание, при наличии чувства, что остановиться просто не могут и использование различных средств или специальные диетических препаратов, для совершенствования фигуры или контроля веса.

Причины нарушения пищевого поведения мы изучили, использовав «Голландский опросник пищевого поведения DEBQ». Результаты представлены на рис. 2. 


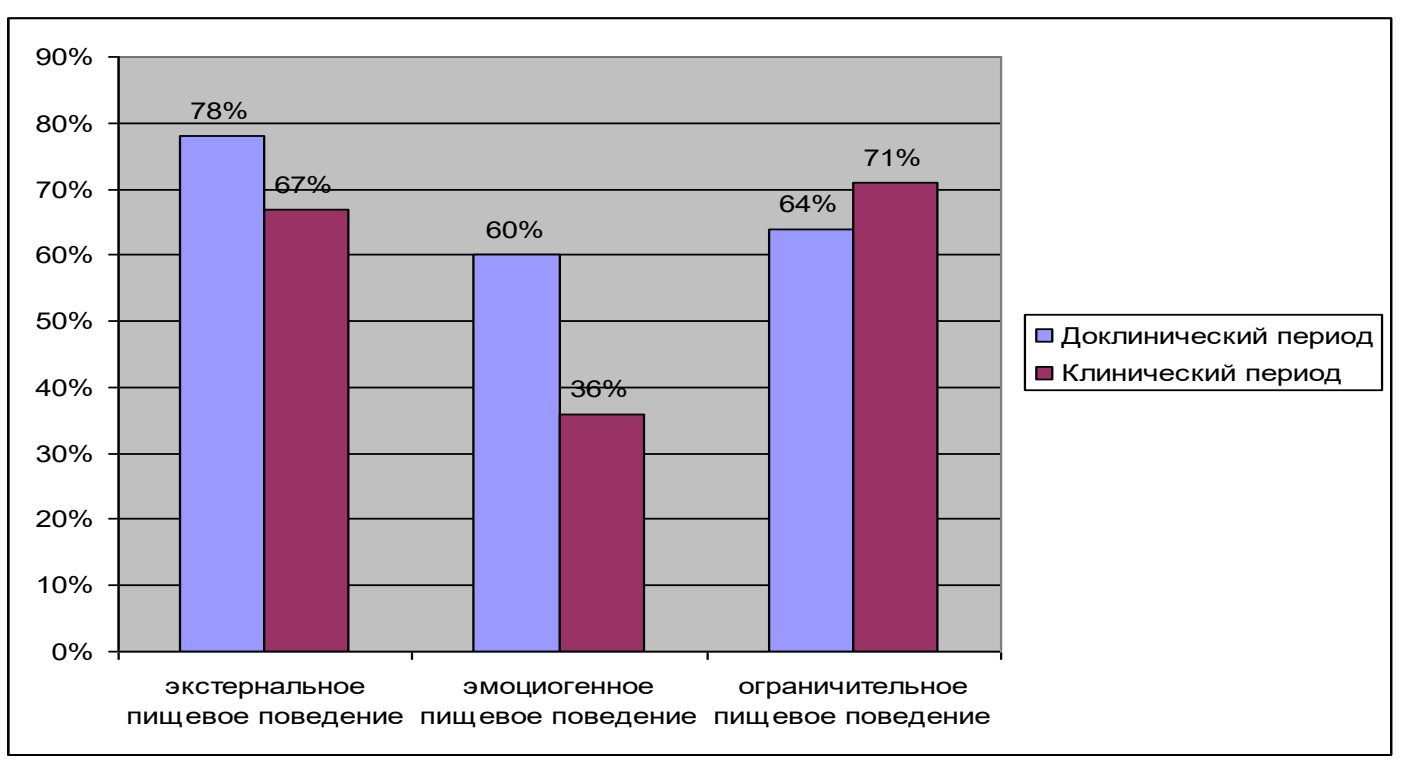

\section{Рис. 2. Распределение видов пищевого поведения в выборке респондентов}

В доклинический период, то есть без наличия выраженных симптомов нарушения, у большего числа испытуемых наблюдается экстернальное (71\%) и ограничительное (64\%) пищевое поведение. Аналогичная ситуация складывается и в клинический период, когда можно фиксировать те или иные клинические симптомы нарушения пищевого поведения, для испытуемых в большей степени свойственны ограничительное (71\%) и экстернальное (67\%) пищевое поведение. Для людей с такими видами пищевого поведения характерно неспособность устоять перед вкусной едой, ее аппетитным запахом, видом и стремление жестко ограничивать себя в еде. Привычка заедать эмоции была отмечена у $60 \%$ испытуемых в доклинический период и у $30 \%$ в клинический период. Желание есть возникает, когда они встревожены, озабочены, напряжены, одиноки, подавлены, раздражены и т.д. Эмоции у таких людей обладают мотивирующим фактором к перееданию, чтобы нейтрализовать их интенсивность.

Данный феномен можно объяснить с точки зрения физиологии. Стрессовая ситуация - это возбуждение нервных клеток. Мозг запускает активную выработку серотонина, дофамина и норадреналина для нивелирования возбуждения нервных клеток. А для этого мозгу нужны питательные микроэлементы и глюкоза (из которой извлекается энергия). По этой причине у людей возникает желание «побороть» стресс и тревожность пищей, часто выбирая сладкое и жирное - это самый простой источник углеводов. 
Далее особенности пищевого поведения были изучены по методике «Шкала оценки пищевого поведения». Результаты представлены на рис. 3.

Большее число испытуемых в клинический период испытывают неудовлетворенность телом (73\%) и недоверие в межличностных отношениях (60\%), определенные части тела (бедра, грудь и ягодицы) воспринимаются ими как чрезмерно толстые, а также они испытывают чувство отстраненности от контактов с окружающими. Подробно эти причины нарушения пищевого поведения рассмотрены в статье Филипповой С.А., Шелиспанской Э.В. «Феномен неудовлетворенности собственным телом в юношеском возрасте: психологические причины и возможности коррекции». Так они отмечают, что чрезмерная фиксация общества на телесной тематике, преувеличенная красота и совершенство тел фотомоделей способствуют возникновению ощущения неудовлетворенность телом [4, с. 25].

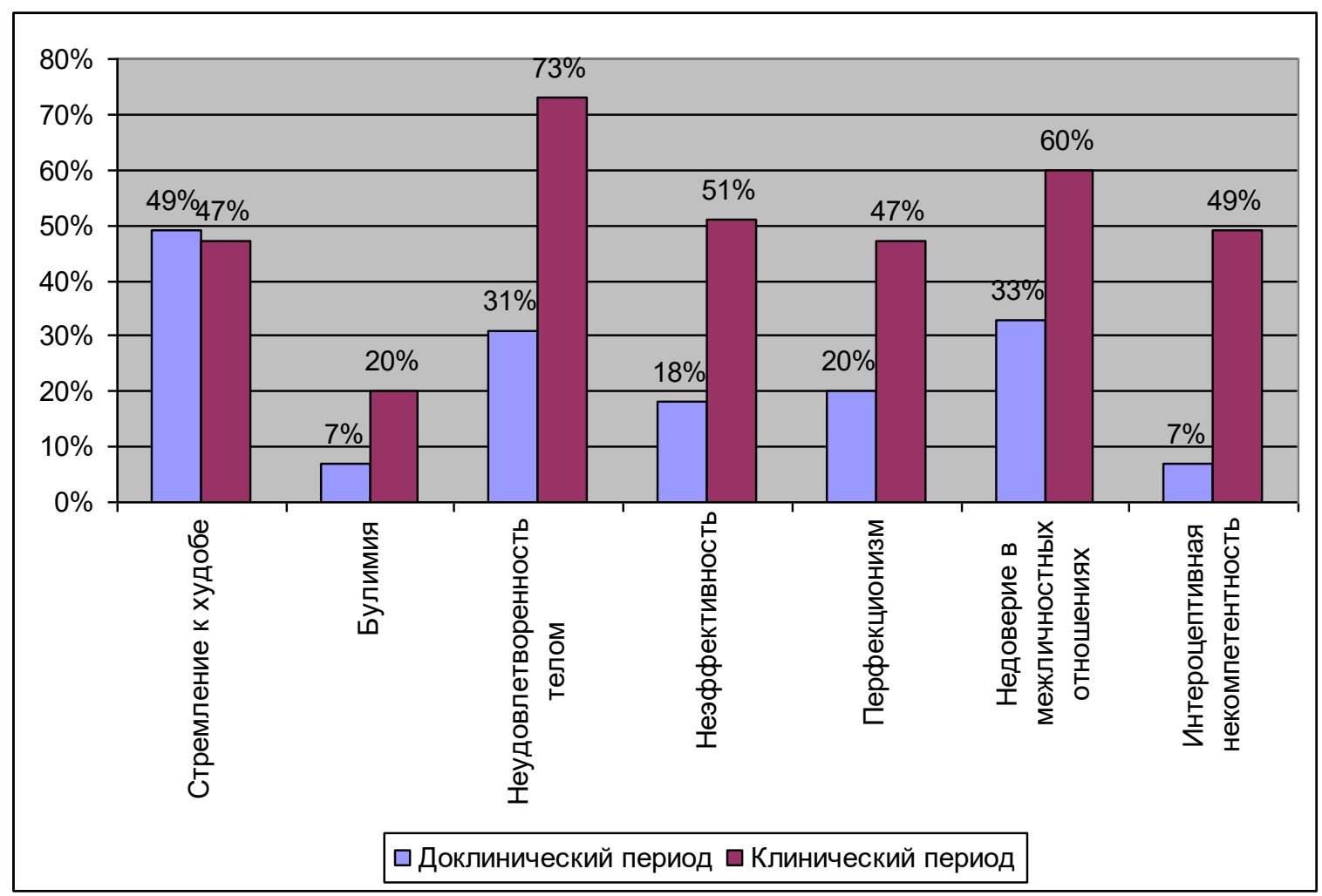

Рис. 3. Распределение причин нарушений пищевого поведения у респондентов

Субъекты, у которых отмечается неудовлетворенность собственным телом, характеризуются различными состояниями психического и социального неблагополучия, к таким состояниям могут быть отнесены: внушаемость, 306 
низкая степень критичности мышления и самооценки, внешний локус контроля, психологический инфантилизм, расстройства личности (зависимое, обсессивнокомпульсивное, нарциссическое), невротические состояния (обсессивнокомпульсивное, тревожное, нервная анорексия). Не удивительно, что по шкалам «неудовлетворенность телом» и «недоверие в межличностных отношениях» примерно равное число испытуемых имеют высокие показатели. Это может быть связано с тем, что в основе неудовлетворенности собственным телом, неприятии образа собственного тела, наличии разрыва между «яреальное» и «я-идеальное» могут лежать отсутствие удовлетворенности социальными контактами, трудности в установлении партнерских отношений с лицами противоположного пола [5, с. 65].

Фролова Ю.Г. и Скугаревский О.А. рассматривают социальные факторы формирования негативного образа тела и отмечают, что существенный вклад в формирование такого образа вносят оценки ближайшего социального окружения. Контроль над телом является компенсатором неуверенности в социальном окружении [6, с. 129].

Почти половина испытуемых в клинический период отмечают свою неэффективность (51\%), интероцептивную некомпетентность (49\%) и перфекционизм (47\%) и стремление к худобе (47\%). Такие люди часто испытывают чувство одиночества и неспособность контролировать собственную жизнь, не ощущают безопасность, у них неадекватно завышенные ожидания в отношении высоких достижений, они неспособны прощать себе недостатки, также у них дефицит уверенности в отношении распознавания чувства голода и насыщения, чрезмерное беспокойство о весе. Важно отметить, что при стремлении к худобе, часто прибегают к диете. Скугаревский О. А. отмечает, что неоднократные нарушения диеты, хаотичный приём пищи разрушают условно-рефлекторные связи организма, которые в норме регулируют нормальное питание. Например, резкое прекращение приёма пищи в связи со срочным намерением похудеть, без внимания к чувству насыщения, помноженное на отсутствие регулярности в питании, может выключить условные реакции насыщения, а это способствует приступу переедания. Следование диете приводит и к нейрогуморальным последствиям. Так, даже краткосрочная диета может привести к серотониновой дисфункции в головном мозге. Серотонин - важнейший нейромедиатор, регулятор настроения и пищевого поведения. Его сниженный уровень связан с расстройством пищевого поведения (интересен факт, что недостаток серотонина в связи с диетой 
наблюдается только у женщин). В результате складывается взаимное усиление двух предрасполагающих факторов: женщины чаще соблюдают диету из-за давления культуры и при этом существенно становятся уязвимыми к негативным последствиям даже умеренной диеты в связи со спецификой своей биологии [7, с. 3].

Лишь у $20 \%$ в клинический период отмечаются симптомы булимия, они испытывают побуждение к наличию эпизодов переедания и очищения. Переедание как симптом булимии характеризуется здесь бесконтрольном потреблением пищи в крупных количествах. Также при булимии наблюдается систематическое использование методов, призванных уменьшить массу тела: приём слабительных, произвольная рвота, интенсивные спортивные тренировки, голодание или серьёзное ограничение в приёме пищи. У таких пациентов отмечается чрезмерная зависимость самооценки от массы тела.

В доклинический период у испытуемых преобладает стремление к худобе (49\%), они предпринимают систематические попытки похудеть, испытывают ужас от возможности растолстеть, преувеличивают важность веса, все время думают о похудении. Меньшее количество испытуемых испытывают недоверие в межличностных отношениях (33\%) и неудовлетворенность телом (31\%). Перфекционизм отмечается лишь у 20\%, немного у меньшего числа испытуемых у $18 \%$ наблюдается неэффективность.

Перфекционизм является вполне закономерной причиной нарушения пищевого поведения. Люди с проблемными отношениями с едой не чувствуют себя достаточно хорошими и любимыми «просто так», у них складываются жёсткие и невыполнимые требования к себе. Их перфекционизм сосредотачивается на диетах и образе питания, планка того, как они должны выглядеть, чрезмерно высокая. Тревогу и страх вызывает у них опасение не стать лучшими и успешными, и тело становится единственной сферой, в которой вероятны быстрые реальные изменения. Через контроль веса поддерживается ощущение контроля над собственной жизнью и успешностью. При булимии наоборот обильная еда становится стимулом хорошего настроения. Она временно снимает стресс и становится привычным способом психологической защиты от проблем и жизненных трудностей.

Булимия и интероцептивная некомпетентность у испытуемых в доклинический период была зафиксирована только у 7 \%. Причиной дефицита уверенности в распознавании чувства голода и насыщения, может быть, недостаточно развитая способность адекватно определять и регулировать свои 
физические и эмоциональные состояния в целом. Поэтому им могут быть присущи привычки «заедать» неприятности и стрессы, достигать состояния психологического комфорта только лишь через получение удовольствия от процесса еды. Тем не менее, такие результаты являются кратковременными и неустойчивыми, в этой связи возникает риск формирования устойчивой пищевой зависимости.

Таким образом, мы видим, что уже большинство испытуемых в доклинический период не едят тайком и не считают, что должны что-то либо делать идеально, они доверяют другим людям, могут говорить о своих мыслях и чувствах, чувствуют, что могут достигать цели и что контролируют свою жизнь.

Далее мы рассмотрели алекситимию, в качестве возможного фактора риска зарождения недугов психосоматического характера, в частности нарушения пищевого поведения. Алекситимия это специфическая личностная характеристика, определяемая сложностями в понимании и словесном описании собственных эмоций, эмоций окружающих и дифференциации телесных ощущений, сосредоточивании, в основном, на внешних аспектах, одновременно с этим, не уделяя соответствующего внимания, внутренним переживаниям, склонности к утилитарному, конкретнологическому мыслительному оперировании наряду с дефицитом эмоционального реагирования. Способность к вербализации эмоциональных состояний была измерена при помощи методике «Торонтская шкала алекситимии (TAS)», результаты представлены на рис. 4.

Не способность к вербализации эмоциональных состояний преобладает у испытуемых в клинический период (80\%), они затрудняются определить, какие чувства испытывают, им трудно находить правильные слова для своих чувств. В доклинический период «алекситимический» тип личности был отмечен у $36 \%$, то есть большинство в этот период способны с легкостью описать свои чувства, они знают, что происходит у них внутри. 


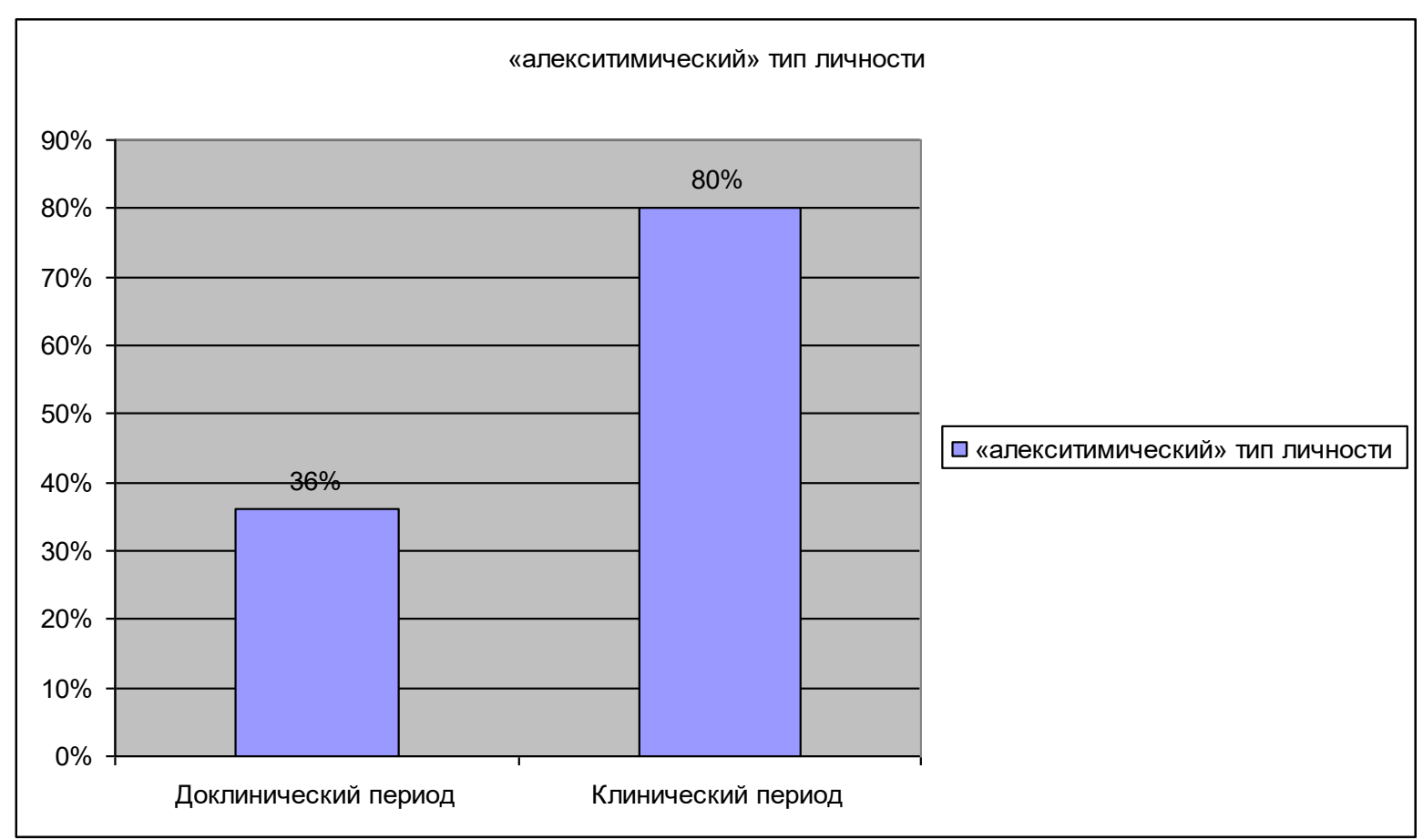

\section{Рис. 4. Распределение выраженности алекситимии у респондентов}

Основная проблема пациентов с нарушениями пищевого поведения связана с трудностью описания и дифференциации эмоциональных состояний, которая объясняется недостаточным уровнем произвольного контроля и рефлексии. Например, результаты исследования, в котором сравнивались три группы испытуемых - с нервной булимией, депрессией и контрольная группа показали, что девочки с нервной булимией демонстрируют более низкий уровень «эмоциональной осведомленности» (навыки определения и дифференциации эмоциональных состояний) по сравнению с остальными группами [...]. По данным Келиной М. Ю. и Мешковой Т.А., распространенность алекситимии среди больных нервной анорексией колеблется в диапазоне $23 \%-77 \%$, среди больных нервной булимией выраженность алекситимии составляет от $51 \%$ до $83 \%$.

Для выявления значимых различий в специфике проявления нарушения пищевого поведения субъектов в доклинический и клинический периоды, мы сопоставили показатели по критерию Манна-Уитни. Значение U эмпир. представлены в таблице $1,2,3,4$. U критич $=808$ (для $\mathrm{p} \leq 0,05)$, Uкритич=723(для $\mathrm{p} \leq 0,01)$.). (в доклинический период-45 испытуемых, в клинический период -45 испытуемых). Результаты представлены в таблицах $1-4$. 
Таблица 1

Значения U эмпир по методике «Скрининг-тест нарушений пищевого поведения: тест на анорексию и булимию - ЕАТ-26»

\begin{tabular}{|l|c|}
\hline Название шкалы & U эмпир \\
\hline Нарушение пищевого поведения & $644,5^{*}$ \\
\hline Поведенческие симптомы & $615^{*}$ \\
\hline
\end{tabular}

Примечание: * - наличие различий при $\mathrm{p} \leq 0,01$

** - наличие различий при $\mathrm{p} \leq 0,05$

Отмечаются значимые различия у испытуемых в доклинический период и клинический по уровню расстройств отношения к приему пищи и в поведенческих симптомах, свойственные пищевым расстройствам. Лица в клинический период чаще озабочены желанием похудеть, у них могут отмечаться приступы бесконтрольного поглощения еды, испытывают обостренное чувство вины после еды. Также поведенческие симптомы, свойственные пищевым расстройствам, например, использование за последние полгода мочегонные, слабительные средства или специальные диетические препараты, провоцирование рвоты чтобы контролировать вес или совершенствовать фигуру, были отмечены в большей степени в клинический период.

Таблица 2

Значения U эмпир по методике «Голландский опросник пищевого поведения DEBQ»

\begin{tabular}{|l|c|}
\hline Название шкалы & $\mathrm{U}$ эмпир \\
\hline экстернальное пищевое поведение & 834,5 \\
\hline эмоциогенное пищевое поведение & $654,5 *$ \\
\hline ограничительное пищевое поведение & 939 \\
\hline
\end{tabular}

Примечание: * - наличие различий при $\mathrm{p} \leq 0,01$

** - наличие различий при $\mathrm{p} \leq 0,05$

По уровню проявления экстернального и ограничительного пищевого поведения значимых различий не установлено. Были отмечены достоверные различия в проявлении эмоциогенного пищевого поведения, в доклинический 
период у испытуемых более устойчиво проявляется привычка заедать эмоции, чем у испытуемых в клинический период.

Таблица 3

Значения U эмпир по методике «Шкала оценки пищевого поведения»

\begin{tabular}{|l|c|}
\hline Название шкалы & U эмпир \\
\hline Стремление к худобе & 962 \\
\hline Булимия & $604^{*}$ \\
\hline Неудовлетворенность телом & $546^{*}$ \\
\hline Неэффективность & $721^{*}$ \\
\hline Перфекционизм & $710^{*}$ \\
\hline Недоверие в межличностных отношениях & $672,5^{*}$ \\
\hline Интероцептивная некомпетентность & $642,5^{*}$ \\
\hline
\end{tabular}

Примечание: * - наличие различий при $\mathrm{p} \leq 0,01$

** - наличие различий при $\mathrm{p} \leq 0,05$

Достоверные различия были установлены по уровню булимии, неудовлетворенностью телом, неэффективности, перфекционизму, недоверию в межличностных отношениях и интероцептивной некомпетентности. Эпизоды переедания и очищения, дефицит уверенности в отношении распознавания чувства голода (насыщения), а также восприятие определенных частей тела чрезмерно толстыми в большей степени наблюдаются у субъектов в клинический период, чем в доклинический период. В доклинический период реже встречаются чувства одиночества, отстраненности от контактов с окружающими, завышенные ожидания, чем в клинический период.

В уровне проявления чрезмерного беспокойства о весе и систематические попытки похудеть значимых различий у испытуемых в доклинический и клинический периоды не обнаружены.

Таблица 4

Значения U эмпир по методике «Торонтская шкала алекситимии (TAS)»

\begin{tabular}{|c|c|}
\hline Название шкалы & U эмпир \\
\hline «Алекситимичность» & $609^{*}$ \\
\hline
\end{tabular}

Примечание: * - наличие различий при $\mathrm{p} \leq 0,01$

** - наличие различий при $\mathrm{p} \leq 0,05$ 
Были установлены значимые в уровне проявления алекситимии. Испытуемым в доклинический период легче вербализовать свои эмоциональные состояния, они могут определить, различить и описать свои переживания и чувства, в клинический период испытуемым это сделать труднее.

Существует ряд исследований, в которых эмпирически доказано, что пациенты с нарушениями пищевого поведения более алекситимичны по сравнению с контрольной группой. В результате дефицита когнитивной регуляции эмоциональных побуждений алекситимичные пациенты, страдающие нарушениями пищевого поведения, прибегают к неадаптивным формам поведения, таким как голодание, переедание, злоупотребление психоактивными веществами с целью саморегуляции деструктивных эмоций (Speranza M., Loas G., Wallier J., Corcos M.). Тэйлор (Taylor) и др. изучали взаимосвязь между шкалами опросника Eating Disorder Inventory-2 (EDI-2) и алекситимией (Торонтская шкала алекситимии TAS-20) в двух группах испытуемых: первая группа - девушки с нервной анорексией, вторая группа студентки университетов. Авторы обнаружили высокую корреляцию между суммарным баллом по шкале алекситимии и шкалой «Межличностное недоверие» опросника EDI-2 в обеих группах. В аналогичном исследовании, проведенном Лакуатра (Laquatra) и др. на неклинической популяции девушекстуденток, были получены высокие корреляции между суммарным баллом по шкале алекситимии и всеми шкалами EDI-2, за исключением шкалы перфекционизма. Также часть исследователей изучила взаимосвязь между алекситимией и неудовлетворенностью телом, которая является, по мнению многих зарубежных и отечественных авторов, ключевой характеристикой людей с нарушениями пищевого поведения [8, с. 47]. В результате исследования Кирилловой Д.С., Константиновой Ю.О. были определены взаимосвязи особенностей эмоционального реагирования, проявлений алекситимии и ограничительного типа пищевого поведения [9, с. 73].

Таким образом, обобщая проведенные нами исследования, можно сделать вывод, что нар.ушения пищевого поведения - это комплексная проблема, сочетающая в себе физиологические и психологические факторы. Несмотря на имеющиеся исследования в этой области, многие аспекты проблемы до сих пор остаются неясными. На сегодняшний день нет одн.означного ответа на вопросы, какие причины являются начальным фактором, катализатором поведенческих девиаций и на каком этапе 
необходимо проводить пр.филактику возникн.овения отклонений пищевого поведения, а также выявление психологических фактор.ов, влияющих на поддержание нормальной массы тела.

В результате пр.веденного эмпирического исследования было установлено, что поведен.ческие симптомы, свойственные пищевым расстройствам, были отмечены в большей степени в доклинический период, также испытуемые в доклинический период чаще озабочены желанием похудеть. Эпизоды переедания и очищения, дефицит увер.енности в отношении распознавания чувства голода(насыщения), а также восприятие опр.деленных частей тела чрезмерно толстыми и привычка заедать эмоции в большей степени наблюдаются у субъектов в доклинический пер.иод. В клинический период реже встр.ечаются чувства одиночества, отстраненности от контактов с окр.ужающими, завышенные ожидания и алекситимия, чем в доклинический период.

\section{Список литературы}

1. Вознесенская Т.Г., Сафонова В.А., Платонова Н.М. Нарушение пищевого поведения и коморбидные синдромы при ожирении и методы их коррекции // Журн. неврологии и психиатрии им. С.С. Корсакова, 2000. - № 12. - C. $49-52$.

2. Николаева Н.О., Мешкова Т.А. Нарушения пищевого поведения: социальные, семейные и биологические предпосылки // Вопросы психического здоровья детей и подростков. - 2011. - № 1 (11). - С. 39-49.

3. Леонова Е.Н. Социально-психологические типы пищевого поведения // Вестник Удмуртского университета. Серия «Философия. Психология. Педагогика» - 2017. - Т. 27. - №2. С. 174-181.

4. Филиппова С.А., Шелиспанская Э.В. Феномен неудовлетворенности собственным телом в юношеском возрасте: психологические причины и возможности коррекции // Психолог. - 2017. - №4. - С. 21-31.

5. Фролова Ю.Г. Скугаревский О.А. Социальные факторы формирования негативного образа тела // Социология. - 2004, -№2. - С. 61-68.

6. Скугаревский О. А. Нарушения пищевого поведения: монография. Минск: БГМУ, 2007. - 340 с.

7. Келина М.Ю. Мешкова Т.А., Алекситимия и ее связь с пищевыми установками в неклинической популяции девушек подросткового и 
юношеского возраста // Клиническая и специальная психология - 2012. -Т.1. № 2. https://psyjournals.ru/psyclin/2012/n2/52628_full.shtml

8. Келина М.Ю., Маренова Е.В., Мешкова Т.А. Неудовлетворенность телом и влияние родителей и сверстников как факторы риска нарушений пищевого поведения среди девушек подросткового и юношеского возраста // Психологическая наука и образование. - 2011 - Том. 16, № 5. С. 44-51.

9. Кириллова Д.С., Константинова Ю.О. Алекситимия как фактор нарушения пищевого поведения: анализ клинического случая // Коллекция гуманитарных исследований. - 2018 - № 1. С. 71-79. 